Research Article

\title{
Early Cracking Risk Prediction Model of Concrete under the Action of Multifield Coupling
}

\author{
Caiyun Jin $\left(\mathbb{D},{ }^{1}\right.$ Jianglin Liu $\mathbb{D}^{2},{ }^{2}$ Zigeng Wang $\left(\mathbb{D},{ }^{2}\right.$ and Yue $\mathbf{L i}^{2}$ \\ ${ }^{1}$ College of Applied Sciences, Beijing University of Technology, No. 100 Pingleyuan Chaoyang District, Beijing 100124, China \\ ${ }^{2}$ The Key Laboratory of Urban Security and Disaster Engineering, MOE, Beijing University of Technology, Beijing 100124, China
}

Correspondence should be addressed to Jianglin Liu; liujl@emails.bjut.edu.cn

Received 31 March 2021; Accepted 5 July 2021; Published 15 July 2021

Academic Editor: Peng Zhang

Copyright (c) 2021 Caiyun Jin et al. This is an open access article distributed under the Creative Commons Attribution License, which permits unrestricted use, distribution, and reproduction in any medium, provided the original work is properly cited.

Through the adiabatic temperature rise experiment, the adiabatic temperature rise of concrete with hydration time was recorded. Based on the maturity degree theory, the relationship between the hydration degree of the concrete and the equivalent age was determined. Then, the hydration degree prediction model of the concrete's early elastic modulus and tensile strength was established. The local temperature and humidity of the concrete were measured by the shrinkage experiment, and based on the capillary water tension theory, a temperature-humidity prediction model for the early shrinkage of the concrete was designed. According to the ratio of the creep deformation and elastic deformation of concrete which were obtained through the restraint ring experiment, a model for predicting the early creep coefficient of concrete was proposed. Based on the coupling effect of "hydration-temperature-humidity," a prediction model of early cracking risk coefficient of concrete under multifield coupling was proposed. Finally, several groups of slab cracking frame experiments were carried out, and the cracking risk prediction results of concrete were consistent with the actual situation, which indicated the correctness of the early cracking risk prediction model of concrete.

\section{Introduction}

The large use of superplasticizers and mineral admixtures, the higher fineness of cement, and the lower water-binder ratio are the typical characteristics of modern concrete. Therefore, the strength of concrete can be significantly improved. However, there are some problems of modern concrete, such as the rapid hydration, the large shrinkage, the rapid internal temperature rises, and the rapid internal humidity decrease, which led to early cracking of concrete. If the early cracks of concrete cannot be strictly controlled, especially the cracks caused by nonload factors in the early stage of concrete structure, the durability and safety of concrete would be reduced [1-5]. Meanwhile, fiber [6] would be used to improve the anticracking property of concrete.

A large number of studies have shown that [7-12] the anticracking property of concrete would be directly or indirectly affected by the change of internal factors such as hydration, temperature, humidity, shrinkage, and creep. Shen et al.'s [10] research found that the curing condition of concrete at $20^{\circ} \mathrm{C}$ had better anticracking properties than that of $45^{\circ} \mathrm{C}$. Zhang et al. [8] established a relationship between the internal humidity of concrete and the free shrinkage strain of concrete at the macro level. The results show that the faster the internal humidity of concrete decreased, the greater the shrinkage at the macro level. Bentz [9] defined the ratio of creep strain to effective shrinkage strain as the creep coefficient of concrete, and the shrinkage of concrete was one of the main factors affecting the cracking, so the early anticracking property of concrete would also be affected by the early creep of concrete. The above research showed that the early anticracking property of concrete had a complex relationship with cement hydration, temperature, humidity, shrinkage, and creep. Many scholars have studied the early anticracking property of concrete with mineral admixtures such as fly ash and slag but have not yet reached a consistent conclusion $[2,13-15]$. Therefore, it is necessary to 
propose an accurate method to predict the early cracking risk of modern concrete.

Liu et al. [16] used the dumbbell method to evaluate the early anticracking performance of concrete materials under constraint conditions. Although this method can quickly evaluate the anticracking property of different concrete materials, it was only aimed at the rapid qualitative detection and analysis of the construction site and cannot quantitatively evaluate the cracking of concrete. Meagher [6] used HIPERPAV software to simulate the influence of admixtures on the early cracking risk of concrete repair plate; Zhang [6] used the ring restraint experiment to evaluate the anticracking property of low shrinkage cement-based materials. Although the above method can evaluate the early anticracking property of concrete, the root cause of the early cracking of concrete cannot be obtained.

Based on (1), Bendimerad et al., [17] neglected the early creep of concrete and considered that the deformation tensile stress $\sigma_{t}(t)$ was only a function of the elastic modulus $E_{(t)}$ and the plastic shrinkage strain $\varepsilon_{s h}(t)$, that is, $\sigma_{t}(t)=E_{(t)} \times \varepsilon_{s h}(t)$, and the plastic shrinkage and cracking risk of recycled aggregate concrete within 24 hours was explored. Which method can predict the risk factor $\eta$ of concrete cracking within 24 hours and the mathematical model of early cracking prediction of concrete has also been defined. However, as the age of concrete increased, the creep of concrete would become larger $[18,19]$, and it also led to the limitation of Ahmed's method to predict the early cracking of concrete due to neglecting creep, which was only applicable to the evaluation of concrete cracking resistance within 24 hours.

$$
\eta=\frac{\sigma_{t}(t)}{f_{t}(t)} .
$$

Therefore, based on the adiabatic temperature rise experiment, shrinkage experiment, and creep experiment of concrete, a prediction model that described the cracking of concrete due to early multifield coupling effects such as "hydration-temperature-humidity" was proposed in this study. The basic cause of concrete early cracking from the mechanism was explained, and the early cracking prediction model of concrete proposed by Bendimerad et al., [17] has been further improved by this prediction model. At the same time, the slab cracking frame experiment method was used to test the cracking resistance of several groups of concrete. Finally, the test results of Khan et al. [20] and Zhang et al. [6] were selected, and the cracking risk prediction model proposed in this study was used to verify the test results of the literature $[6,20]$.

\section{Experiment}

\subsection{Materials and Experiment Design}

2.1.1. Material Properties. The raw materials used for concrete were cement, fly ash, slag, sand, coarse aggregate, superplasticizer, and tap water. The physical and chemical properties of these raw materials were as follows: P.O42.5 ordinary Portland cement conformed with the current
Chinese national standard GB 175-2007 “Common Portland Cement." The $3 \mathrm{~d}$ and $28 \mathrm{~d}$ compressive strength of P.O42.5 ordinary Portland cement was $27 \mathrm{MPa}$ and $49 \mathrm{MPa}$, respectively, and the specific gravity and specific surface area were $3.16 \mathrm{~g} / \mathrm{cm}^{3}$ and $354 \mathrm{~m}^{2} / \mathrm{kg}$ respectively. Grade I fly ash conformed with the current Chinese national standard GB/T 1596-2017 "Fly ash used for cement and concrete." The ignition loss, water demand ratio, and moisture content of fly ash were $3.7 \%, 88 \%$, and $0.4 \%$, respectively; The specific surface area, 7-day activity index, and ignition loss of slag were $425 \mathrm{~m}^{2} / \mathrm{kg}, 78 \%$, and $0.26 \%$, respectively. And the main chemical composition is shown in Table 1 . The fineness modulus of the river sand was 2.56. The particle size of calcareous coarse aggregate was a continuous gradation of 5-20 mm. The polycarboxylate superplasticizer had a water reduction rate of $31 \%$.

2.1.2. Mix Proportion Design of Concrete. According to the concrete mix proportion shown in Table 2, the elastic modulus experiment, axial tensile experiment, adiabatic temperature rise experiment, shrinkage experiment, and creep experiment of concrete were carried out in this study. The above experiments were mainly used to determine the parameters in the prediction model of concrete cracking risk coefficient. Finally, in order to verify the applicability of the early cracking prediction model of concrete, 3 groups of slab cracking frame experiments were carried out according to the concrete mix proportion shown in Table 2 . The dosage of aggregate and cementitious material was determined by the trial mix proportion of the control target based on the strength (when the design strength of concrete was C40, $\mathrm{W} / \mathrm{B}=0.45$; when the design strength of concrete was C60, $\mathrm{W} / \mathrm{B}=0.35$; when the design strength of concrete was $\mathrm{C} 80$, $\mathrm{W} / \mathrm{B}=0.25)$. The slump of TS- 1 , TS- 2 , and TS-3 concrete was $85 \mathrm{~mm}, 88 \mathrm{~mm}$, and $93 \mathrm{~mm}$, respectively. The compressive strength of TS-1, TS-2, and TS- 3 concrete was 42.3 $\mathrm{MPa}$, 63.5 $\mathrm{MPa}$, and $81.7 \mathrm{MPa}$, respectively.

\subsection{Experiment Method}

2.2.1. Tensile Strength and Elastic Modulus Experiment of Concrete. According to the current Chinese national standard for "Standard for test method of mechanical properties on ordinary concrete" (GB/T50081-2016), based on the mix proportion shown in Table 2 , the elastic modulus and tensile strength of concrete in $1 \mathrm{~d}, 3 \mathrm{~d}, 5 \mathrm{~d}, 7 \mathrm{~d}, 14 \mathrm{~d}, 21 \mathrm{~d}$, and $28 \mathrm{~d}$ were tested.

2.2.2. Adiabatic Temperature Rise Experiment of Concrete. According to the current Chinese national standard for "Test code for hydraulic concrete" (SL 352-2006), based on the 3 types of concrete mix proportions shown in Table 2, $50 \mathrm{~L}$ concrete samples were selected for the adiabatic temperature rise experiment. At the early stage of the experiment, the adiabatic temperature rise was recorded every $0.5 \mathrm{~h}$, and every $5 \mathrm{~h}$ after $24 \mathrm{~h}$, until the end of the adiabatic temperature rise experiment, which lasted a total of 7 days. The 
TABLE 1: Main chemical composition of cementitious material (mass fraction\%).

\begin{tabular}{lcccccc}
\hline Materials & $\mathrm{CaO}$ & $\mathrm{SiO}_{2}$ & $\mathrm{Al}_{2} \mathrm{O}_{3}$ & $\mathrm{Fe}_{2} \mathrm{O}_{3}$ & $\mathrm{SO}_{3}$ & $\mathrm{MgO}$ \\
\hline Cement & 59.98 & 23.6 & 7.21 & 3.07 & 2.14 & 2.07 \\
Fly ash & 2.93 & 55.10 & 20.5 & 7.7 & 0.28 & 2.25 \\
Slag & 42.49 & 38.61 & 7.27 & 0.4 & 0.9 & 0.71 \\
Silica fume & 0.40 & 95.00 & 0.40 & 0.80 & 0.50 & 0.30 \\
\hline
\end{tabular}

TABLE 2: Mix proportion of concrete $\left(\mathrm{kg} / \mathrm{m}^{3}\right)$.

\begin{tabular}{lcccccccc}
\hline No. & W/B & Cement & Fly ash & Slag & Silica fume & Sand & Coarse aggregate & Superplasticizer \\
\hline TS-1 & 0.45 & 250 & 65 & 65 & 0 & 920 & 930 & 6 \\
TS-2 & 0.35 & 270 & 85 & 95 & 0 & 830 & 930 & 8 \\
TS-3 & 0.25 & 360 & 90 & 100 & 50 & 770 & 920 & 12 \\
\hline
\end{tabular}

Note. TS-1, TS-2, and TS-3 represented 3 experiment mix proportions of concrete, respectively.

adiabatic temperature rise experiment device is shown in Figure 1(a). The temperature sensor in the figure was used to record the adiabatic temperature rise value of the concrete. The temperature compensation circuit and the heat insulation layer were mainly used to avoid the loss of hydration heat of concrete.

2.2.3. Shrinkage Experiment of Concrete. The coupling effect of the early "temperature-humidity" field of concrete was considered in this study, according to the current Chinese national standard for "Test code for hydraulic concrete" (SL 352-2006), based on the 3 types of concrete mix proportions shown in Table 2, the concrete shrinkage deformer as shown in Figure 1(b) [8] was used, the size of the concrete specimen was $100 \mathrm{~mm} \times 100 \mathrm{~mm} \times 515 \mathrm{~mm}$, and a temperature and humidity senor was installed in the center of the specimen, which can automatically collect the deformation, temperature, and humidity at the inner center of the concrete. The room temperature was about $22^{\circ} \mathrm{C}$, and the relative humidity was about $60 \%$. The shrinkage of concrete in $1 \mathrm{~d}, 3 \mathrm{~d}, 5 \mathrm{~d}, 7 \mathrm{~d}$, $14 \mathrm{~d}, 21 \mathrm{~d}$, and $28 \mathrm{~d}$ was recorded.

2.2.4. Creep Experiment of Concrete. Gawin et al. [21] proposed a mathematical calculation method for creep of concrete, which decomposed the total creep strain rate tensor into two parts: viscoelastic strain rate and viscous flow strain rate. Li et al. [11] analyzed the early creep performance of concrete by using the ring restraint experiment, which showed that this method can not only ensure the accuracy of the early creep of concrete measured by the experiment but also be simpler than the calculation method of concrete early creep proposed by Gawin et al. [21]. Therefore, the ring restraint experiment was also adopted in this study, and the early creep experiment of concrete was carried out according to the concrete mix proportion shown in Table 2.

2.2.5. Early Cracking Experiment of Concrete. According to the current Chinese national standard for "Standard for test method for long-term performance and durability of ordinary concrete" (GB/T 50082-2009) in this study, a slab cracking frame as shown in Figure 1(c) was selected. The size of the cracking frame was $900 \mathrm{~mm} \times 700 \mathrm{~mm} \times 100 \mathrm{~mm}$. The side plates, bolts, and stiffening rib were mainly used to fix the steel formwork of the cracking frame, and the crack inducer was mainly used to induce the early cracking of concrete due to shrinkage. This experiment was mainly to observe the cracking conditions after the initial setting of concrete and was used to verify the correctness of the cracking risk prediction model proposed in this paper. The room temperature was about $22^{\circ} \mathrm{C}$, and the relative humidity was about $60 \%$. When the concrete cracked, the test observation stopped.

\section{Establishment of Cracking Risk Coefficient Prediction Model}

3.1. The Establishment of Early Cracking Risk Prediction Model of Concrete. According to the criterion of concrete cracking [17], the cracking risk coefficient $\eta$ was used to evaluate the early cracking resistance of modern concrete, as shown in the following equation:

$$
\begin{aligned}
\eta & =\frac{\sigma_{t}(t)}{f_{t}(t)} \\
& =\frac{E_{(t)} \times \varepsilon_{\text {sh-e }}(t)}{f_{t}(t)},
\end{aligned}
$$

where $\sigma_{t}(t)$ is the deformation tensile stress (cracking driving force) of concrete at the early age $t, \mathrm{MPa} ; f_{t}(t)$ is the tensile strength of concrete at the early age $t, \mathrm{MPa} ; E_{(t)}$ is the elastic modulus of the concrete at the early age $t, \mathrm{MPa}$; $\varepsilon_{\text {sh-e }}(t)$ is the effective shrinkage strain of the concrete at the early age $t$. Among them, when $\eta<0.7$, the concrete does not crack; when $0.7 \leq \eta \leq 1.0$, the concrete may crack; when $\eta>1.0$, the concrete cracks.

Gao et al.'s [22, 23] research showed that the effective shrinkage strain $\varepsilon_{\text {sh-e }}(t)$ was the result of the interaction of the shrinkage strain and the creep strain (strain of concrete due to creep) of the concrete, as shown in

$$
\varepsilon_{\text {sh-e }}(t)=\varepsilon_{\text {sh }}(t)-\varepsilon_{\text {creep }}\left(t, t_{0}\right),
$$

where $t$ and $t_{0}$ are the age of concrete and the age of concrete under loading, respectively, $d ; \varepsilon_{s h}(t)$ is the shrinkage strain of the concrete at the age $t ; \varepsilon_{\text {creep }}\left(t, t_{0}\right)$ is the shrinkage strain of the concrete due to creep in the early age $\left(t, t_{0}\right)$. 


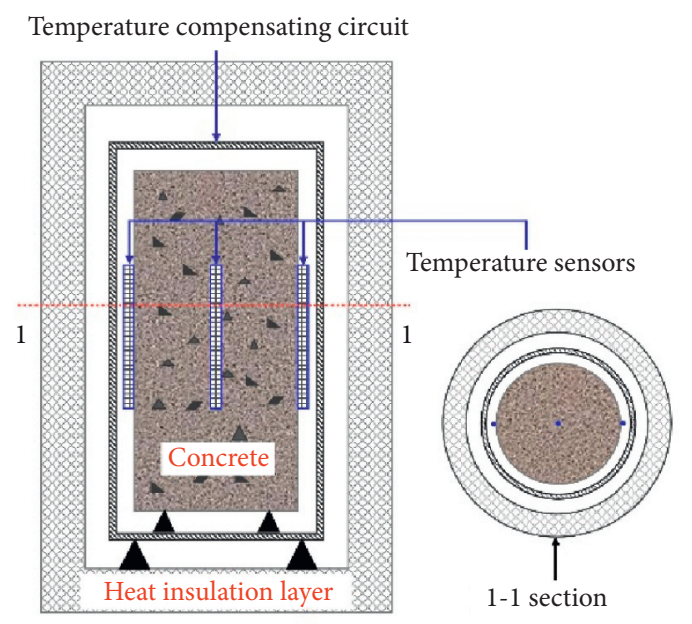

(a)

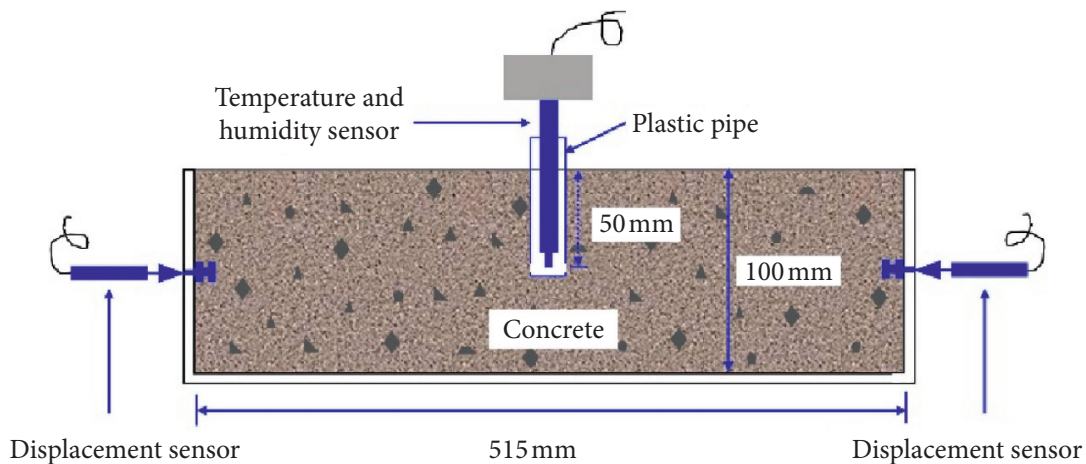

(b)

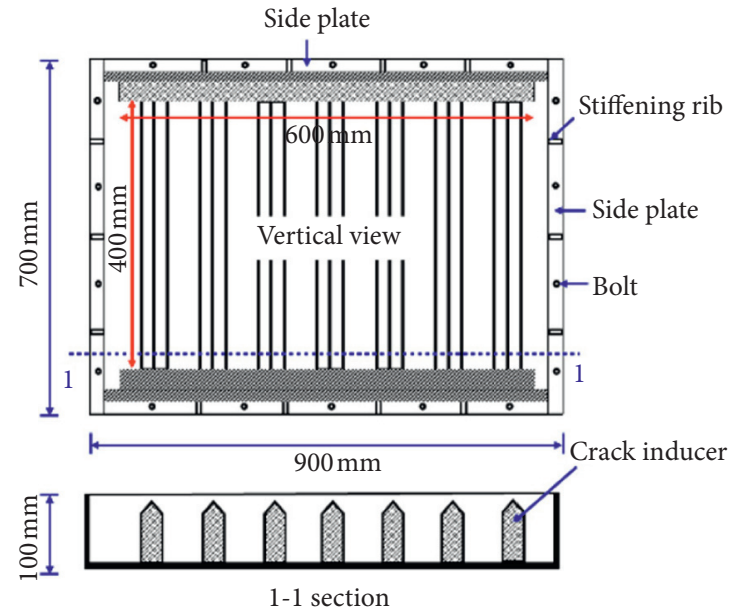

(c)

Figure 1: Schematic diagram of the test device. (a) Adiabatic temperature rise experiment for concrete. (b) Shrinkage experiment of concrete. (c) Slab cracking frame experiment of concrete.

Bentz et al.'s $[9,23]$ study showed that the relationship between creep strain and effective shrinkage strain can be expressed by creep coefficient $\varphi$, as shown in

$$
\phi_{\left(t, t_{0}\right)}=\frac{\varepsilon_{\text {creep }}\left(t, t_{0}\right)}{\varepsilon_{\text {sh-e }}\left(t, t_{0}\right)},
$$

where $\phi_{\left(t, t_{0}\right)}$ is the creep coefficient of concrete at an early age $\left(t, t_{0}\right)$.

It can be known from equations (3) and (4) that the expression of the relationship between the effective shrinkage strain $\varepsilon_{\text {sh-e }}$ of concrete at an early age $\left(t, t_{0}\right)$ is shown as follows: 


$$
\varepsilon_{s h-e}\left(t, t_{0}\right)=\frac{\varepsilon_{s h}(t)}{1+\phi_{\left(t, t_{0}\right)}} .
$$

Equation (5) was substituted into equation (2), and the risk prediction model of early cracking of modern concrete was obtained as follows:

$$
\eta=\frac{E_{(t)} \cdot \varepsilon_{s h}(t)}{f_{t}(t) \cdot\left(1+\phi\left(t, t_{0}\right)\right)} .
$$

Therefore, based on the prediction model of concrete cracking proposed by Ahmed [17], the effect of creep on the early cracking of concrete was further considered, and the prediction model of modern concrete cracking risk with creep coefficient was put forward innovatively. In Section 3.2 , based on the coupling effect of multifields such as "hydration-temperature-humidity-force" in the early stage of concrete, the elastic modulus $E_{(t)}$, tensile strength $f_{t}(t)$, shrinkage strain $\varepsilon_{\text {sh }}(t)$, and creep coefficient $\phi_{\left(t, t_{0}\right)}$ of concrete at age $t$ would be determined.

\subsection{Multifield Coupling Control Mechanism and Determination of Mechanical Parameters}

3.2.1. Experiment Results of Adiabatic Temperature Rise and Determination of Cement Hydration Degree. The adiabatic temperature rise experiment results of TS-1, TS-2, and TS-3 concrete are shown in Figure 2. Based on the adiabatic temperature rise experiment of concrete, the hydration degree $\alpha$ of cement can be expressed as [7]

$$
\alpha=\frac{\Delta T_{(t)}}{\Delta T_{\infty}}
$$

where $\Delta T_{(t)}$ is the adiabatic temperature rise value of the concrete temperature rise sample at the age $t,{ }^{\circ} \mathrm{C} ; \Delta T_{\infty}$ is the adiabatic temperature rise value reached when the concrete is fully hydrated, ${ }^{\circ} \mathrm{C}$.

However, the cement in the concrete cannot be completely hydrated $[7,24]$. It was assumed that when the adiabatic temperature rise of the concrete reached $\Delta T_{\max }$, the cement hydration was completed, and the final hydration degree $\alpha_{u}$ of the cement can be expressed as

$$
\alpha_{u}=\frac{\Delta T_{\max }}{\Delta T_{\infty}} .
$$

An important typical characteristic of modern concrete was used of mineral admixtures. Schindler and Folliard [25] had studied a lot of research on the final hydration degree of cement in modern concrete mixed with slag and fly ash, and the final hydration degree model of cement containing slag and fly ash was proposed as follows:

$$
\alpha_{u}=\frac{1.031 \cdot(W / C)}{0.194+(W / C)}+0.50 \cdot P_{F}+0.30 \cdot P_{S} \leq 1.0
$$

where $W / C$ represents the mass ratio of water and cement in concrete; $P_{F}$ represents the mass percentage of fly ash in cement in total cementitious materials; $P_{S}$ represents

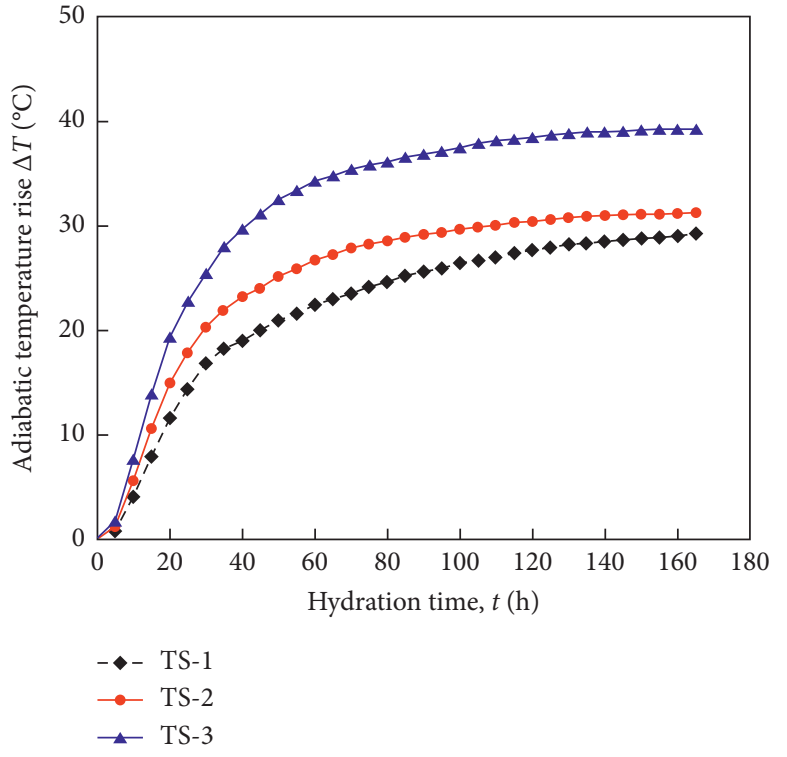

FIgURE 2: Adiabatic temperature rise curve of concrete.

the percentage of slag in cement in total cementitious materials.

Luzio and Cusatis [26] concluded that the final hydration degree of cement in concrete mixed with silica fume was expressed as follows:

$$
\alpha_{\alpha}=\frac{1.032 \cdot W / C-0.279(s / c) \alpha_{s}^{\infty}}{0.194+W / C},
$$

where $\alpha_{s}^{\infty}$ is the final reaction degree of silica fume, which was expressed as follows [27]:

$$
\alpha_{s}^{\infty}=S F^{\mathrm{eff}} \min \left[1, \frac{(S / C)_{\mathrm{req}}}{(S / C)}\right],
$$

where $S F^{\text {eff }}$ is the "effective coefficient" of silica fume, that is, the mass fraction of $\mathrm{SiO} 2$ in silica fume; $(S / C)_{\text {req }}=\min (0.16,0.4(W / C))$.

According to equations (7) and (8), the relationship between the hydration degree $\alpha(t)$ of cement at age $t$ and the final hydration degree $\alpha_{u}$ of the cement can be expressed as

$$
\alpha(t)=\alpha_{u} \frac{\Delta T_{(t)}}{\Delta T_{\max }},
$$

where $\Delta T_{(t)}$ and $\Delta T_{\max }$ can be obtained from the adiabatic temperature rise curve. Theoretically, the longer the adiabatic temperature rise experiment duration, the more accurate the measured value of $\Delta T_{\max }$ was.

However, under different temperature histories of the same mix ratio, the internal cement hydration degree was different at the same age. Therefore, based on the maturity theory, the concept of equivalent age was introduced to eliminate the influence of the temperature history of concrete on its concrete internal hydration. The age $t$ required for cement hydration in concrete under different temperature histories was equivalent to the age $t_{\mathrm{eq}}$ required for concrete under reference temperature (usually $20^{\circ} \mathrm{C}$ ), and its calculation expression was as follows [7]: 


$$
t_{\mathrm{eq}}=\int_{0}^{t} e \frac{1}{R}\left(\frac{U_{\mathrm{ar}}}{293}-\frac{U_{\mathrm{aT}}}{273+T}\right) \mathrm{d} t,
$$

where $t_{\mathrm{eq}}$ is the equivalent age, $d ; R$ is the ideal gas constant, $8.314 \mathrm{~J} /(\mathrm{mol} \cdot \mathrm{K}) ; U_{\text {ar }}$ is the activation energy of the internal cement hydration reaction at the reference temperature of the concrete; $T$ is the temperature of the concrete, ${ }^{\circ} \mathrm{C} ; U_{\mathrm{aT}}$ is the activation energy of the internal cement hydration reaction at temperature $T$ of the concrete.

Kim [28] found that the apparent activation energy can be regarded as a constant in the early stage of cement hydration. However, with the hydration reaction proceeds of the cement, the effects of temperature $T$ and curing time on the apparent activation energy of the cement need to be considered. At this time, $U_{\mathrm{aT}}$ can be expressed as

$$
U_{a T}=(42830-43 T) e^{(-0.00017 T) t},
$$

where $t$ is the curing age, $d$. The continuous curve of (13) was divided into $n$ segments, the interval of each segment is $\left(t_{i}-t_{i-1}\right)$, and the expression as shown in (15) was obtained:

$$
t_{e q}=\sum_{i=1}^{n} e \frac{1}{R}\left(\frac{U_{a r}}{293}-\frac{U_{a T}}{273+T}\right) \cdot\left(t_{i}-t_{i-1}\right) .
$$

Pane and Hansen [29] explored the relationship between the hydration degree $\alpha$ of cement and the equivalent age $t_{\text {eq }}$, a model of the equivalent age and adiabatic temperature rise experiment of the cement hydration degree was established, and the relationship expression as shown in equation (16) was proposed:

$$
\alpha(t)=\alpha_{u} e\left(\frac{A}{t_{\mathrm{eq}}}\right)^{B},
$$

where the constants of $A$ and $B$ were obtained by fitting the model according to the above equation.

Therefore, the research ideas were as follows in this section, the fresh concrete was placed in the adiabatic temperature rise experiment chamber, and then the temperature inside the adiabatic temperature rise experiment chamber was recorded by the temperature sensor, and the relationship curve between adiabatic temperature rise values and hydration time was drawn. The final hydration degree $\alpha_{u}$ of concrete was calculated according to equation (10), and then the hydration degree $\alpha(t)$ corresponding to each hydration time was determined according to equation (12). At the same time, based on the maturity theory, the concept of equivalent age was introduced to eliminate the influence of the temperature history of concrete on its internal cement hydration degree. According to equation (15), the equivalent age $t_{\mathrm{eq}}$ corresponding to the actual hydration time was determined. Finally, based on (16), the parameters $A$ and $B$ were determined; that is, the mathematical model of concrete hydration degree and equivalent age was determined.

To sum up, according to the adiabatic temperature rise curve shown in Figure 2 and equations (7)-(16) in Section 3.1 , the test value and fitting curve of cement hydration degree and equivalent age are obtained as shown in Figure 3,

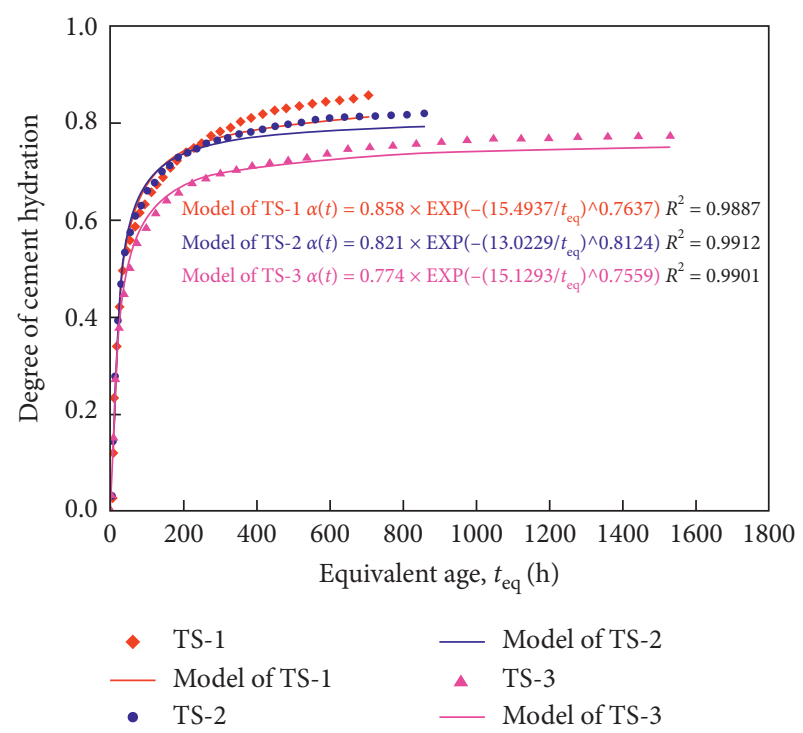

Figure 3: Test value and fitting value of cement hydration degree and equivalent age in the concrete of TS- 1 concrete, TS- 2 concrete, and TS-3 concrete.

and the relevant parameters and model fitting parameters are listed in Table 3.

The $R^{2}$ values of the model result and the test result in Figure 3 were not less than 0.98 , indicating that the correlation was very high. It can be seen that the model of cement hydration degree and equivalent age proposed by Pane [29] can be well described the development law of cement hydration degree and equivalent age in different concrete mix proportions, and the effect of temperature history on cement internal hydration degree of the concrete can be eliminated.

\subsubsection{Determination of Early Elastic Modulus Prediction} Model of Concrete. Zhang and Schutter [7, 30] have explored the relationship between the mechanical properties (elastic modulus, tensile strength, etc.) of concrete and the hydration degree of cement. Therefore, according to the test results of the elastic modulus of concrete, the hydration degree method was used to describe the early elastic modulus of concrete. The prediction model of the hydration degree of the elastic modulus was as follows:

$$
E(\alpha)=\beta_{E} \cdot E_{28} \cdot\left(\frac{\alpha-\alpha_{0}}{\alpha_{u}-\alpha_{0}}\right)^{b},
$$

where $E(\alpha)$ is the elastic modulus of concrete when the degree of cement hydration is $\alpha, \mathrm{MPa} ; \beta_{E}$ is the subsequent increase coefficient of the elastic modulus of concrete after 28 days, 1.05; $E_{28}$ is the elastic modulus of concrete after 28 days of curing, GPa; $\alpha_{0}$ is the hydration degree at the initial setting of the concrete; $\alpha_{u}$ is the final hydration degree of the concrete; $b$ is a constant obtained by fitting the hydration degree model of the concrete's elastic modulus to the test values. The measured value and fitting curve of elastic modulus of concrete are shown in Figure 4, and the relevant 
TABLE 3: Test parameters and fitting parameters of concrete.

\begin{tabular}{lcccccc}
\hline No. & $\alpha_{0}$ & $\alpha_{u}$ & $A$ & $B$ & $b$ & $d$ \\
\hline TS-1 & 0.152 & 0.858 & 14.49 & 0.76 & 1.575 & 1.144 \\
TS-2 & 0.125 & 0.821 & 13.02 & 0.81 & 1.910 & 1.434 \\
TS-3 & 0.106 & 0.529 & 15.13 & 0.76 & 1.350 & 1.175 \\
\hline
\end{tabular}

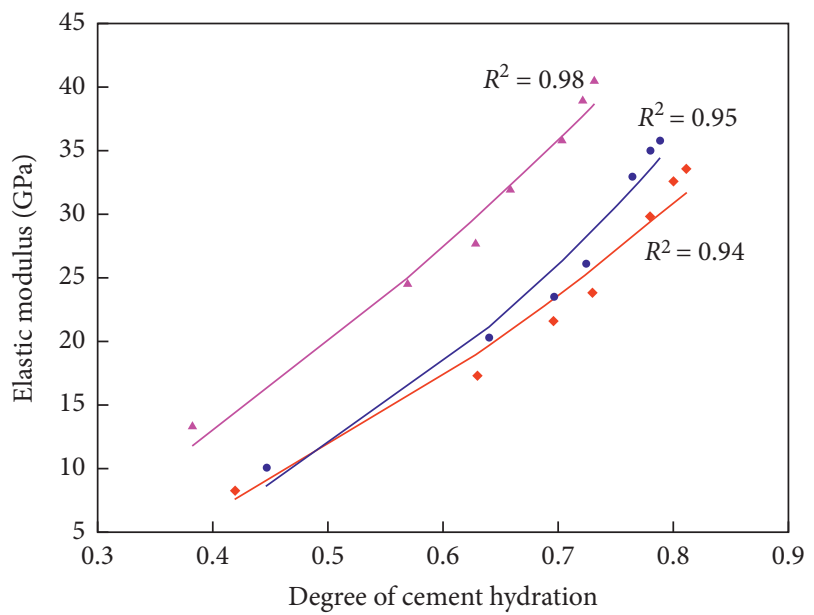

$$
\begin{array}{ll}
\text { TS-1 } & - \text { Model of TS-2 } \\
\text { - Model of TS-1 } & \text { TS-3 } \\
\text { - TS-2 } & - \text { Model of TS-3 }
\end{array}
$$

FIgURE 4: Test and fitting values of concrete elastic modulus and hydration degree of TS- 1 concrete, TS- 2 concrete, and TS-3 concrete.

parameters and model fitting parameters are listed in Table 3.

In Figure 4, R2 of TS-1, TS-2, and TS-3 model results and test values were $0.94,0.95$, and 0.98 , respectively, with high correlation. It can be seen that the early elastic modulus prediction model of concrete proposed by Zhang and Schutter $[7,30]$ can be well described the relationship between the elastic modulus and hydration degree of concrete.

\subsubsection{Determination of Early Tensile Strength Prediction} Model of Concrete. According to the test results of the tensile strength of concrete, the hydration degree of concrete was used to describe the early tensile strength. The prediction model of the tensile strength was $[17,31]$

$$
f(\alpha)=\beta_{f} \cdot f_{28} \cdot\left(\frac{\alpha-\alpha_{0} d}{\alpha_{u}-\alpha_{0}}\right),
$$

where $f(\alpha)$ is the tensile strength of concrete when the degree of cement hydration is $\alpha, \mathrm{MPa} ; \beta_{f}$ is the subsequent increase coefficient of the tensile strength of concrete after 28 days, 1.05; $f_{28}$ is the tensile strength of concrete after 28 days of curing, $\mathrm{GPa}$; the meaning of $\alpha_{0}$ and $\alpha_{u}$ was shown in equation (17); $d$ is a constant obtained by fitting the hydration degree model of the concrete's tensile strength to the test values. The measured tensile strength and fitting curve of concrete are shown in Figure 5, and the relevant parameters and model fitting parameters are listed in Table 3.

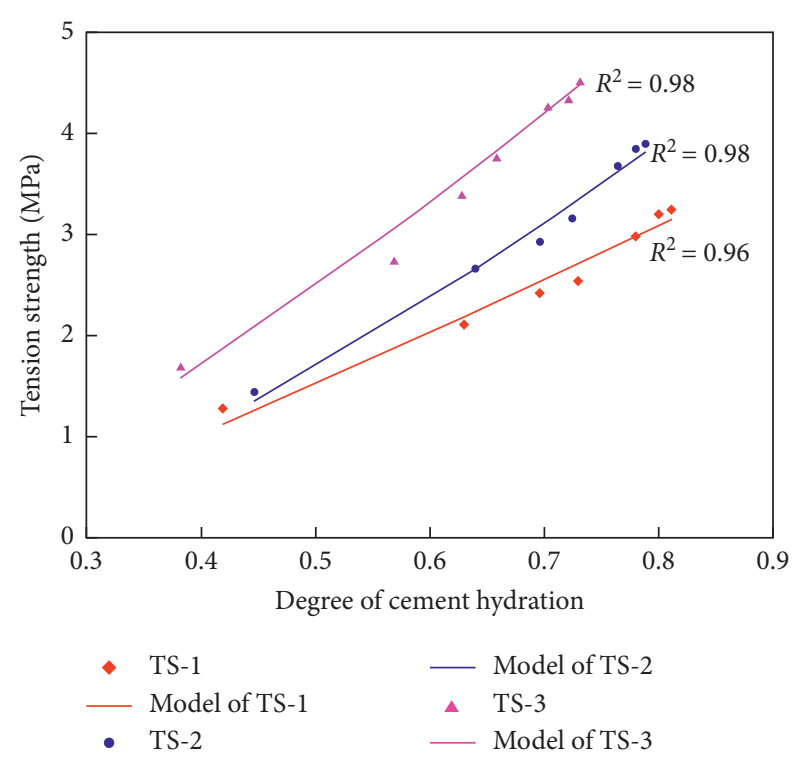

FIgURE 5: Test and fitting values of concrete tensile strength and hydration degree of TS-1 concrete, TS-2 concrete, and TS-3 concrete.

The R2 values of model results and test values in Figure 5 were not less than 0.95 , and the correlation between the predicted results and test results was very high. It can be seen that the early tensile strength prediction model of concrete proposed by Zhang and Schutter [7, 30] can be well described the relationship between concrete tensile strength and hydration degree.

\subsubsection{Early Shrinkage Prediction Model of Concrete.} Zhang [8] considered that the change of the internal humidity of concrete was the root cause of the early autogenous shrinkage and dry shrinkage of concrete, and the relationship between early shrinkage of concrete and internal humidity was explored by using a normal experiment environment without temperature control. The results showed that although the internal humidity of the concrete changed gradually along the thickness direction of the specimen, the local humidity can be used to estimate the shrinkage strain of the concrete specimen at the macro level, and then the shrinkage stress of the structure can be calculated. Bentz et al., [32] used capillary water tension theory to predict the shrinkage deformation of concrete. The results showed that the concrete shrinkage value can be calculated by knowing the internal relative humidity of the concrete. Therefore, based on the coupling effect of the "temperaturehumidity" field in the early stage of the concrete, the capillary water tension theory was used to establish the early shrinkage strain prediction model of the concrete according to the local temperature and humidity of the concrete.

(1) Shrinkage Prediction Model of Concrete Based on Humidity Field. The change of internal relative humidity of concrete would lead to the change of capillary water tension. The relationship between the internal humidity of concrete and the age measured by the shrinkage experiment in this study is 
shown in Figure 6. The mechanical model of the concrete element under the tension of capillary water is shown in Figure 7. The calculation process of concrete element shrinkage caused by capillary water tension was as follows: where $d_{x}, d_{y}$, and $d_{z}$ are the side lengths of the concrete element.

$$
V_{0}=d_{x} \cdot d_{y} \cdot d_{z}
$$

When the volume of a concrete element changes due to internal humidity, the shrinkage strains of the concrete element along the $X$-axis, $Y$-axis, $Z$-axis directions were assumed as $\varepsilon_{x}, \varepsilon_{y}$, and $\varepsilon_{z}$, respectively, and the volume $V$ of the concrete element at this time was

$$
V=d_{x}\left(1+\varepsilon_{x}\right) \cdot d_{y}\left(1+\varepsilon_{y}\right) \cdot d_{z}\left(1+\varepsilon_{z}\right) .
$$

Therefore, the volume strain $\varepsilon_{V}$ (change of unit volume) of the concrete was

$$
\begin{aligned}
\varepsilon_{V} & =\frac{V-V_{0}}{V_{0}} \\
& =\varepsilon_{x}+\varepsilon_{y}+\varepsilon_{z}+\varepsilon_{x} \cdot \varepsilon_{y}+\varepsilon_{y} \cdot \varepsilon_{z}+\varepsilon_{x} \cdot \varepsilon_{z} .
\end{aligned}
$$

After the concrete element was loaded, the shrinkage strain of the concrete element along the $X$-axis, $Y$-axis, and $Z$-axis directions was

$$
\begin{aligned}
& \varepsilon_{x}=\frac{1}{E}\left(\sigma_{x}-\mu\left(\sigma_{y}+\sigma_{z}\right)\right), \\
& \varepsilon_{y}=\frac{1}{E}\left(\sigma_{y}-\mu\left(\sigma_{x}+\sigma_{z}\right)\right), \\
& \varepsilon_{z}=\frac{1}{E}\left(\sigma_{z}-\mu\left(\sigma_{x}+\sigma_{y}\right)\right),
\end{aligned}
$$

where $E$ is the static elastic modulus of the concrete, $\mathrm{GPa} \mu \mu$ is Poisson's ratio of the concrete, taking $0.2[33] ; \sigma_{x}, \sigma_{y}$, and $\sigma_{z}$ represent the capillary water tension of the concrete element in the $X$-axis, $Y$-axis, and $Z$-axis directions.

The higher-order terms of equation (21) were ignored, equations (22)-(24) were substituted into (21), and the volume strain of concrete was obtained as follows:

$$
\begin{aligned}
\varepsilon_{V} & =\varepsilon_{x}+\varepsilon_{y}+\varepsilon_{z} \\
& =\frac{1-2 \mu}{E}\left(\sigma_{x}+\sigma_{y}+\sigma_{z}\right) \\
& =\frac{\left(\sigma_{x}+\sigma_{y}+\sigma_{z}\right)}{3 K},
\end{aligned}
$$

where the bulk modulus $K=E / 3(1-2 \mu)$, GPa.

Assuming that the strains in each direction of concrete shrinkage were equal. Under the action of capillary water tension $\sigma$, the shrinkage strain $\varepsilon_{w}$ in the $X$-axis, $Y$-axis, and $Z$-axis directions was

$$
\varepsilon_{w}=\frac{\sigma}{3 K}
$$

Lura et al. [33] considered that the capillary pores caused by chemical shrinkage of the cementitious material internal the concrete were completely wetted, and the contact angle between water and solids was 0 . At this time, the capillary water tension of the concrete was

$$
\sigma=-\frac{\rho R(273+T) \ln R H}{M},
$$

where $\sigma$ is the capillary water tension of concrete; $\rho$ is the density of water, $\mathrm{kg} / \mathrm{m}^{3} ; R$ is the ideal gas constant, $8.314 \mathrm{~J} /$ $(\mathrm{molK}) ; T$ is the internal temperature of the concrete as shown in Figure $6,{ }^{\circ} \mathrm{C}$; $\mathrm{RH}$ is the internal relative humidity of the concrete as shown in Figure 6; $M$ is the molar mass of water, g/mol.

However, concrete was a heterogeneous material and contains pores in it, so the bulk modulus $K$ of the concrete in equations (25)-(26) needed to be modified [34]. Meanwhile, because the water in the pores was consumed at the hydration of cement in the early stage, making the pores tend to be unsaturated [31], it was necessary to introduce saturation $S$ to further modify the shrinkage strain of concrete in (26). Therefore, the equation after modify of concrete was (shrinkage prediction model of concrete based on humidity field)

$$
\varepsilon_{w}=S \cdot \frac{\sigma}{3 K}
$$

where $\sigma$ is the capillary water tension of the concrete, which was calculated according to equation (27); the specific calculation process of the modified bulk modulus $\mathrm{K}$ and the saturation S was shown in equations (29)-(30).

The reciprocal of the modified bulk modulus $K[4,34]$ was

$$
\frac{1}{K}=\frac{1}{K_{C}}-\frac{1}{K_{s}},
$$

where $K$ is the bulk modulus used for calculating the shrinkage strain of concrete in equation (28); the bulk modulus $K_{C}=E_{C} / 3(1-2 \mu)$, where $E_{C}$ is the elastic modulus of concrete (calculated according to (17)); $\mu$ is Poisson's ratio of concrete, taking 0.2 [33], the units of $K_{C}$ and $E_{C}$ are $\mathrm{GPa} ; K_{S}$ is the bulk modulus of the solid material, taking $44 \mathrm{GPa}$ [33].

The saturation $S[35]$ was

$$
S=\frac{p-0.7(1-p) \alpha}{p-0.5(1-p) \alpha},
$$

where $p=(W / C) /(W / C)+\left(\rho_{W} / \rho_{C}\right), W / C$ is the mass ratio of water and cement, $\rho_{W} / \rho_{C}$ is the density ratio of water and cement, and $\alpha$ is the hydration degree of concrete.

(2) Shrinkage Prediction Model of Concrete Based on Temperature Field. Based on the shrinkage experiment of concrete, the relationship between the internal temperature of concrete and its age was measured in this study as shown in Figure 6. The finite element method was used by Liu et al. $[36,37]$ to predict the anticracking property of concrete. The thermal expansion coefficient of concrete was regarded as a constant, and the values were $9.94 \mu \varepsilon /{ }^{\circ} \mathrm{C}$ and $10 \mu \varepsilon /{ }^{\circ} \mathrm{C}$. Li [11] determined that the thermal expansion coefficient of C30 and C80 


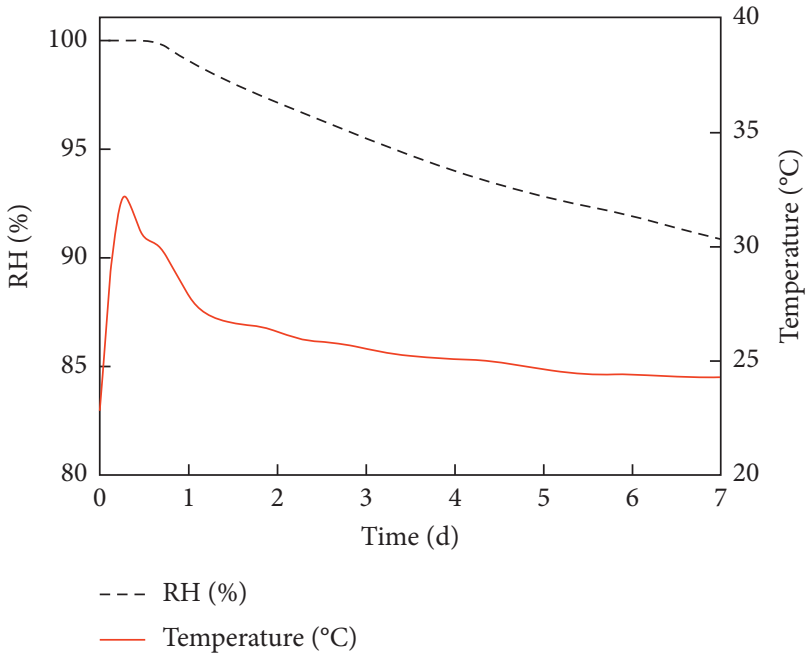

(a)

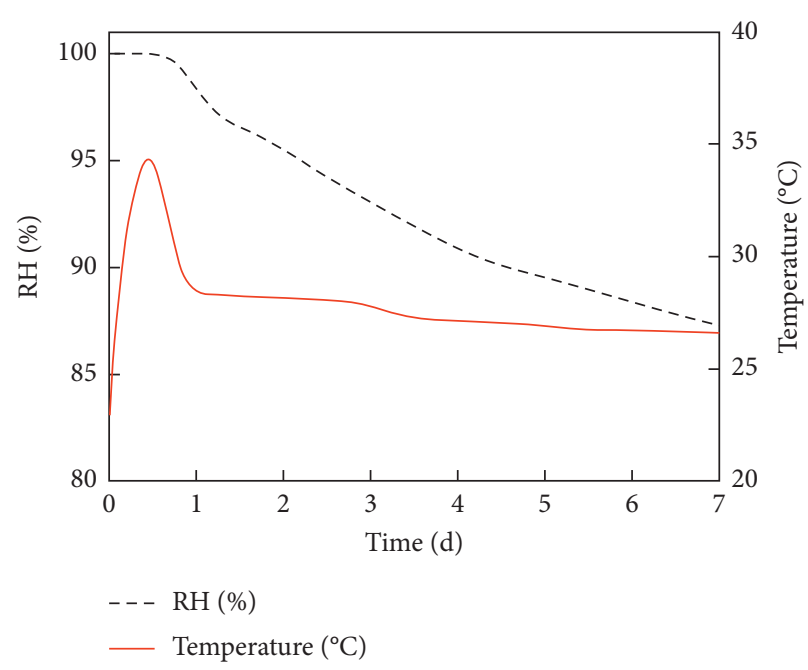

(b)

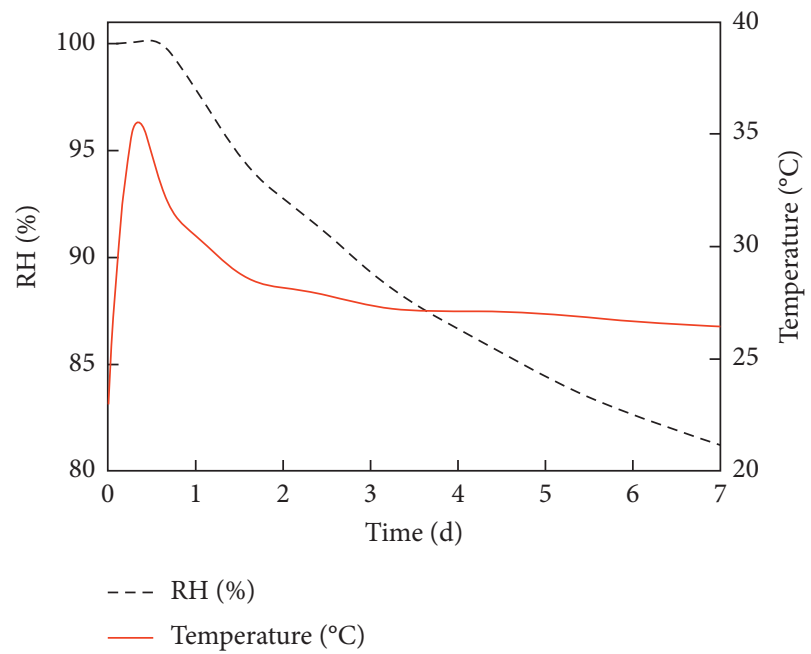

(c)

Figure 6: The relation curve of concrete internal humidity-temperature and age. (a) TS-1 concrete. (b) TS-2 concrete. (c) TS-3 concrete.

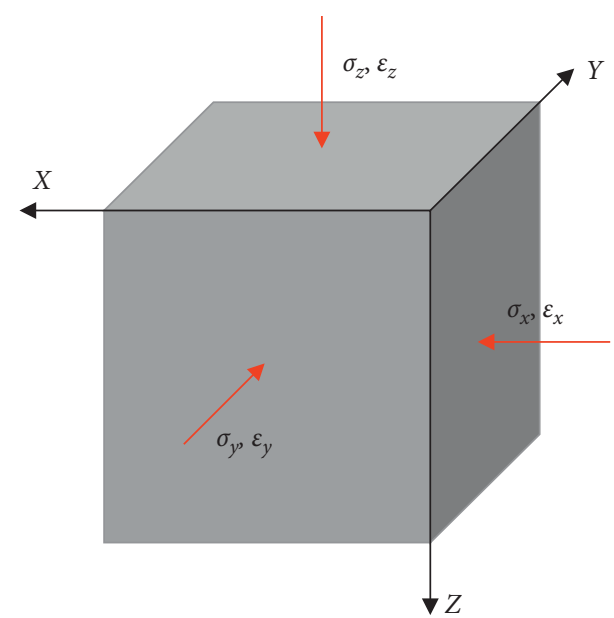

FIGURE 7: Schematic diagram of capillary water tension of concrete element. concrete was between $10 \mu \varepsilon /{ }^{\circ} \mathrm{C}$ and $12 \mu \varepsilon /{ }^{\circ} \mathrm{C}$ through the variable temperature experiment of concrete. Therefore, the thermal expansion coefficient was taken as $10 \mu \varepsilon /{ }^{\circ} \mathrm{C}$ in this study, and it was applied to the prediction model of concrete shrinkage. At this time, the temperature deformation $\varepsilon_{T}$ of concrete with temperature history between $\left(T_{0}, T\right)$ was (shrinkage prediction model of concrete based on temperature field)

$$
\begin{aligned}
\mathcal{E}_{T} & =\int_{T_{0}}^{T} \beta_{T} \mathrm{~d} T \\
& =\int_{T_{0}}^{T} 10 \mathrm{~d} T \\
& =10 \cdot\left(T-T_{0}\right) \\
& =10 \cdot \Delta T,
\end{aligned}
$$

where $\beta_{T}$ is the thermal expansion coefficient of concrete, $\mu \varepsilon /{ }^{\circ} \mathrm{C} ; T_{0}$ is the internal temperature of the concrete at the initial setting, ${ }^{\circ} \mathrm{C}$; $T$ is the internal temperature of the 
concrete at time $t,{ }^{\circ} \mathrm{C}$; and $\Delta T$ is the difference between $T$ and $T_{0},{ }^{\circ} \mathrm{C}$.

(3) Determination and Verification of Early Shrinkage Prediction Model of Concrete. In this study, the shrinkage prediction model of concrete was determined based on the humidity field (based on the capillary water tension theory) and the temperature field in Section 3.2.4 (2), and the shrinkage prediction model of concrete in the early stage under the coupling effect of "temperature-humidity" field was obtained as follows:

$$
\varepsilon=\varepsilon_{w}+\varepsilon_{T}=S \cdot \frac{\sigma}{3 K}+10 \cdot \Delta T .
$$

Therefore, based on equation (32), according to the relationship curve of temperature-humidity and age shown in Figure 6, combined with the hydration degree prediction model of concrete elastic modulus, the prediction value of concrete shrinkage strain shown in Figure 8 was obtained, which showed that the test results almost coincided with the prediction results, indicating that the method of using the local temperature and humidity inside the concrete to predict the macro shrinkage of the component was feasible and also verified the accuracy of the early shrinkage prediction model of concrete, which was consistent with the conclusion of Zhang [8].

\subsubsection{Determination of Early Creep Prediction Model of} Concrete. In this study, based on the ring restraint test results in Section 2.2.4, the creep coefficient of concrete was defined as the ratio of creep deformation to elastic deformation under circumferential constraint [9]. The early creep coefficient of concrete obtained by the test is shown in Figure 9. According to the early creep results of concrete explored by Jiang et al. [38], the concrete creep coefficient was fitted with an exponential model, and the specific fitting equation was as follows:

$$
\varphi_{t}=D_{1} \cdot e^{\left(-t / D_{2}\right)}+\varphi_{0},
$$

where $\varphi_{t}$ represents the creep coefficient of concrete at time $t ; D_{1}, D_{2}$, and $\varphi_{0}$ are parameters obtained by fitting the test values based on the exponential model (equation (33)), and the fitting results are shown in Table 4.

The $R^{2}$ values of the predicted results and test values in Figure 9 were not less than $95 \%$, and the correlation between the predicted results and test results was very high. It can be seen that the early creep prediction model of concrete proposed by Schutter $[7,30]$ can well describe the relationship between concrete early creep and age.

\subsection{Determination of Cracking Risk Prediction Model of} Concrete under the Action of Multifield Coupling. According to the coupling effect of multiple-fields such as "hydration-temperature-humidity-force" in the early stage of concrete, and based on equation (6), from the perspective of the change mechanism of the internal hydration degree, temperature, and humidity of the concrete, the cracking risk prediction model of modern concrete was proposed as follows:

$$
\begin{aligned}
\eta & =\frac{E_{(t)} \cdot \varepsilon_{s h}(t)}{f_{t}(t) \cdot\left(1+\phi_{\left(t, t_{0}\right)}\right)} \\
& =\frac{\left(\beta_{E} \cdot E_{28} \cdot\left(\left(\alpha-\alpha_{0}\right) /\left(\alpha_{u}-\alpha_{0}\right)\right)^{b}\right) \times(S \cdot(\sigma / 3 K)+10 \cdot \Delta T)}{\left(\beta_{f} \cdot f_{28} \cdot\left(\left(\alpha-\alpha_{0}\right) /\left(\alpha_{u}-\alpha_{0}\right)\right)^{d}\right) \times\left(1+\left(D_{1} \cdot e^{\left(-t / D_{2}\right)}+\phi_{0}\right)\right)} .
\end{aligned}
$$

\section{Verification of the Cracking Risk Prediction Model of Modern Concrete}

In this study, a slab cracking frame was used for the early cracking experiment of concrete, and the cracking of TS-1, TS-2, and TS-3 concrete after the initial setting was recorded. Based on equation (6), according to the elastic modulus, tensile strength, macro shrinkage strain, and creep coefficient of concrete, the experimental value of the concrete cracking risk coefficient was calculated. Meanwhile, based on equation (34), according to the hydration degree, temperature, humidity, and creep of concrete in the early stage, the predicted value of the concrete cracking risk coefficient was calculated. Finally, according to the cracking risk coefficients calculated by equations (6) and (34), they were compared with the cracking state measured by the slab cracking frame experiment to verify the accuracy of the early cracking risk prediction model of concrete. In addition, the experiment results of Khan [20] and Zhang [6] were selected in this paper, and the cracking risk prediction model proposed in this study was used to verify the test results of the literature $[6,20]$.

4.1. Cracking the State of Concrete in the Slab Cracking Frame Experiment. The cracking state of the concrete in the slab cracking frame experiment is shown in Figure 10. The TS-1 mix proportion was used for the slab cracking frame experiment, and the concrete began to crack on the third day. The TS- 2 mix proportion was used for the slab cracking frame experiment, and the concrete cracks appeared on the first day. The TS-3 mix proportion was used for the slab cracking frame experiment, and the concrete had cracks on the first day.

4.2. Verification of the Cracking Risk Prediction Model of Concrete. Based on the test results of the elastic modulus, tensile strength, shrinkage strain, creep coefficient, and adiabatic temperature rise values of the concrete, the cracking risk coefficients calculated according to equations (6) and (34) are shown in Table 5. Khan et al. [20] believed that the early cracking of concrete was caused by creep and shrinkage. Finally, the correctness of his opinion was verified by the finite element method. Based on the restraint ring experiment, the concept of equivalent shrinkage strain (equivalent shrinkage strain was $K \times \mathcal{E}$, where $K$ is the creep coefficient of concrete) was proposed by Zhang et al. [6], and 


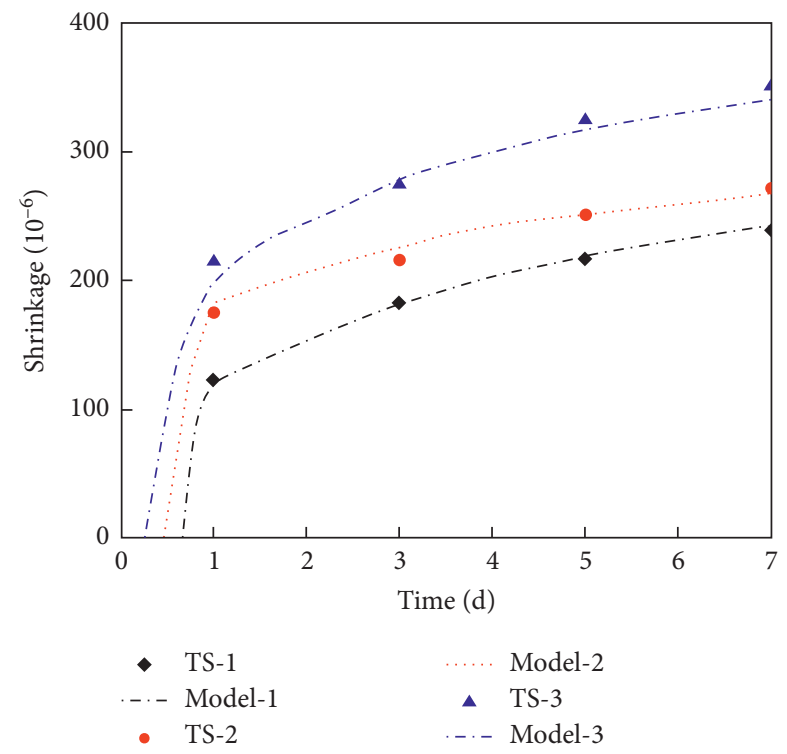

FIgURE 8: Experimental and predicted values of concrete shrinkage and age.

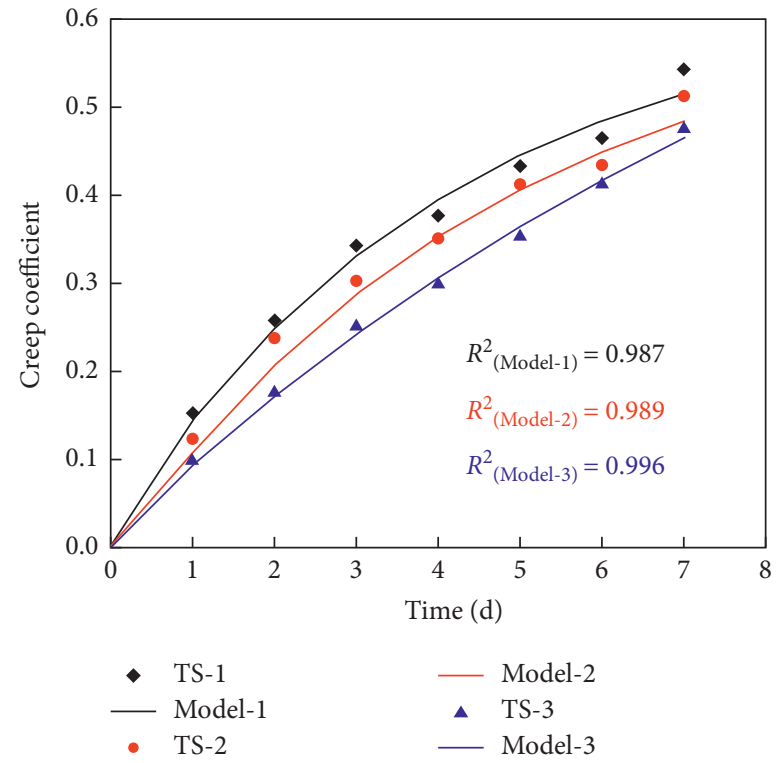

FIGURE 9: Experimental and fitting values of the relationship between early creep and age of concrete.

TABLE 4: Test parameters and fitting parameters of concrete.

\begin{tabular}{lccr}
\hline No. & $D_{1}$ & $D_{2}$ & $\varphi_{0}$ \\
\hline TS-1 & -0.6176 & 4.0831 & 0.6270 \\
TS-2 & -0.6250 & 4.7436 & 0.6333 \\
TS-3 & -0.9237 & 10.1974 & 0.9302 \\
\hline
\end{tabular}

the anticracking property of ECC (traditional engineered cementitious composite) and LSECC (low shrinkage engineered cementitious composite) concrete was evaluated by mathematical calculation model. Therefore, the test results of Khan et al. [20] and Zhang et al. [6] were selected in this study, the cracking risk prediction model proposed in this paper was adopted, and the test results of literature $[6,20]$ were further verified. The calculation data and results of cracking risk are listed in Table 5.

It can be seen from Table 5 that the early cracking risk coefficient of concrete calculated based on equations (6) and (34) was basically consistent with the actual cracking time 


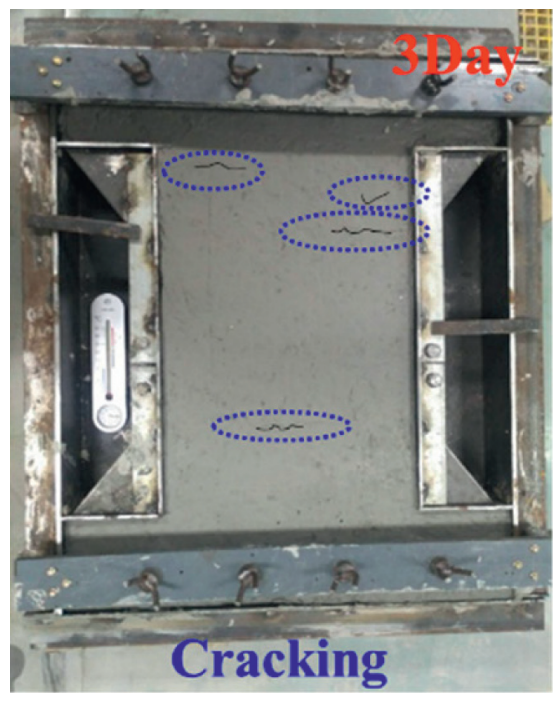

(a)

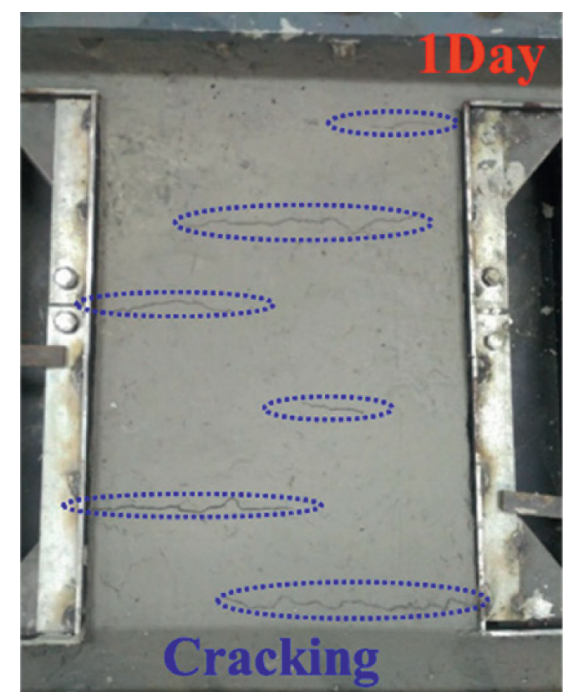

(b)

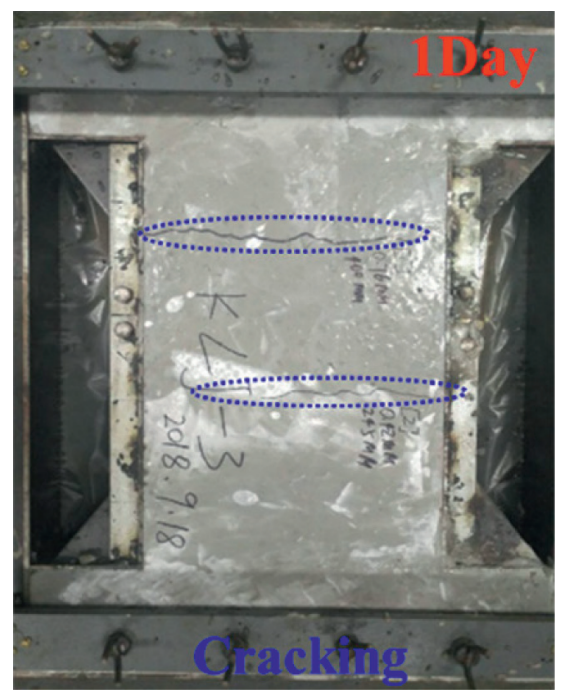

(c)

FIgURE 10: The cracking state of the concrete in the slab cracking frame. (a) TS-1 concrete; (b) TS-2 concrete; (c) TS-3 concrete.

and cracking state of concrete, which showed that the early cracking risk prediction model of the modern concrete can be well predicted the cracking resistance of concrete.

Khan et al. [20] used the restraint ring experiment to test the creep of concrete and found that the concrete just cracked on the 15.5 days. According to the relevant data of literature [20] (as shown in Table 5), and based on the prediction model of cracking risk coefficient proposed in this paper, the cracking risk coefficient of concrete on the 15.5 days was calculated to be 1.0033. According to the cracking criteria of concrete, it can be seen that the concrete just cracks at this time, which was consistent with the results of the literature [20].

Based on the restraint ring experiment, Zhang et al. [6] proposed a mathematical model for predicting the cracking of ECC and LSECC concrete, which predicted that the ECC concrete would crack on the 5 th day, while the cracking time of the experiment was on the 7th day; LSECC concrete mixed with fiber had not been cracked. According to the relevant data of literature [6] (as shown in Table 5), and based on the prediction model of cracking risk coefficient proposed in this paper, the cracking risk coefficient of ECC concrete on the 5 th day was 0.798 , and the cracking risk coefficient on the 7 th day was 2.135; the cracking risk coefficient of LSECC concrete on the 28th day was 0.697 . Therefore, the prediction results showed that ECC concrete could crack on the 5th day, and it was certain that the cracking would occur on the 7 th day, while the cracking of LSECC concrete had not been cracked within $28 \mathrm{~d}$, and the prediction results were consistent with the literature [6], which further showed that the concrete cracking risk prediction model proposed in this paper was correct and reasonable. 
TABLe 5: Test value and verification of early cracking risk coefficient of concrete.

\begin{tabular}{|c|c|c|c|c|c|c|c|c|}
\hline No. & Age (d) & Et $(\mathrm{GPa})$ & $f t(\mathrm{MPa})$ & $\varepsilon\left(\times 10^{-6}\right)$ & $\varphi t$ & Predicted value, $\eta$ & Predicted status & Actual status \\
\hline TS-1 (equation (6)) & 3 & 17.3 & 2.11 & 183 & 0.343 & 1.117 & $\mathrm{C}$ & $\mathrm{C}$ \\
\hline TS-1 (equation (34)) & 3 & 19.02 & 2.36 & 181 & 0.331 & 1.096 & $\mathrm{C}$ & $\mathrm{C}$ \\
\hline TS-2 (equation (6)) & 1 & 10.1 & 1.44 & 175 & 0.123 & 1.093 & $\mathrm{C}$ & $\mathrm{C}$ \\
\hline TS-2 (equation (34)) & 1 & 8.61 & 1.35 & 182 & 0.107 & 1.049 & $\mathrm{C}$ & $\mathrm{C}$ \\
\hline TS-3 (equation (6)) & 1 & 13.3 & 1.68 & 215 & 0.098 & 1.550 & $\mathrm{C}$ & $\mathrm{C}$ \\
\hline TS-3 (equation (34)) & 1 & 12.3 & 1.58 & 197 & 0.092 & 1.404 & $\mathrm{C}$ & $\mathrm{C}$ \\
\hline \multirow[t]{2}{*}{ Khan et al. [20] } & 15.5 & 28 & 3.2 & 305 & 1.16 & 1.003 & $\mathrm{C}$ & $\mathrm{C}$ \\
\hline & Age $(\mathrm{d})$ & $E t(\mathrm{GPa})$ & $f t(\mathrm{MPa})$ & $K \times \varepsilon\left(\times 10^{-6}\right)$ & Type of concrete & Predicted value, $\eta$ & Predicted status & Actual status \\
\hline Zhang et al. [6] & 5 & 17 & 2.45 & 115 & ECC & 0.798 & $\mathrm{PC}$ & $\mathrm{NC}$ \\
\hline Zhang et al. [6] & 7 & 19 & 2.67 & 300 & ECC & 2.135 & $\mathrm{C}$ & $\mathrm{C}$ \\
\hline Zhang et al. [6] & 28 & 18.9 & 4.45 & 164 & LSECC & 0.697 & $\mathrm{NC}$ & $\mathrm{NC}$ \\
\hline
\end{tabular}

Note. "TS-1 (equation (6))" denotes the cracking risk coefficient of concrete calculated according to equation (6); "TS-1 (equation (34))" denotes the cracking risk coefficient of concrete calculated according to equation (34); "C" denotes cracking of concrete; "PC" denotes possible cracking of concrete; "NC" denotes not cracking of concrete.

\section{Conclusion}

According to the adiabatic temperature rise experiment, shrinkage experiment, creep experiment, and theoretical analysis of concrete, the early cracking risk prediction model of modern concrete was established. The early cracking risk coefficient of concrete calculated by the model was consistent with the actual cracking state based on the slab cracking frame experiment of concrete. The following conclusions were drawn:

(1) Based on the capillary water tension theory, the shrinkage strain of the specimen at the macro level can be estimated by using the local temperature and humidity inside the concrete, and then the shrinkage stress of the structure can be calculated

(2) The concrete cracking risk prediction model with creep coefficient can well predict the early cracking of the concrete

(3) When the concrete mix proportion, adiabatic temperature rise curve, $28 \mathrm{~d}$ elastic modulus, $28 \mathrm{~d}$ tensile strength, internal temperature and humidity curve, and early creep coefficient are known, the cracking risk coefficient of concrete can be well predicted, and then the early cracking resistance of concrete can be evaluated

\section{Data Availability}

The data used to support the findings of this study are included within the article.

\section{Conflicts of Interest}

The authors declare that they have no conflicts of interest.

\section{Acknowledgments}

The authors would like to acknowledge the financial support provided by the National Natural Science Foundation of China (51808015 and 52078015), the general project of science and technology plan of Beijing Municipal
Commission of Education (KM202110005018), and Beijing Natural Science Foundation (8202005).

\section{References}

[1] J. P. Liu, Q. Tian, and C. W. Miao, "Investigation on the plastic shrinkage of cementitious materials under drying conditions: mechanism and theoretical model," Magazine of Concrete Research, vol. 64, no. 6, pp. 550-561, 2012.

[2] G. Li and Z. Wang, "A mesoscopic simulation for the earlyage shrinkage cracking process of high performance concrete in bridge engineering," Advances in Materials Science and Engineering, vol. 2017, Article ID 9504945, 12 pages, 2017.

[3] B. Menu, M. Jolin, and B. Bissonnette, "Assessing the shrinkage cracking potential of concrete using ring specimens with different boundary conditions," Advances in Materials Science and Engineering, vol. 2020, Article ID 4842369, 13 pages, 2020.

[4] Z. M. Li, T. S. Lu, X. H. Liang, H. Dong, and G. Ye, "Mechanisms of autogenous shrinkage of alkali-activated slag and fly ash pastes," Cement and Concrete Research, vol. 135, 2020.

[5] G. Ji, T. Kanstad, and O. Bjontegaard, "Numerical modelling of field test for crack risk assessment of early age concrete containing fly ash," Advances in Materials Science and Engineering, vol. 2018, Article ID 1058170, 16 pages, 2018.

[6] T. Meagher, N. Shanahan, D. Buidens, K. A. Riding, and A. Zayed, "Effects of chloride and chloride-free accelerators combined with typical admixtures on the early-age cracking risk of concrete repair slabs," Construction and Building Materials, vol. 94, pp. 270-279, 2015.

[7] J. Zhang, Y. Han, J. Han, and Z. Wang, "Cement hydration based model to predict the mechanical properties of precast concrete," Magazine of Concrete Research, vol. 66, no. 12, pp. 603-617, 2014.

[8] J. Zhang, H. Dongwei, and S. Wei, "Experimental study on the relationship between shrinkage and interior humidity of concrete at early age," Magazine of Concrete Research, vol. 62, no. 3, pp. 191-199, 2010.

[9] D. P. Bentz, "A review of early-age properties of cement-based materials," Cement and Concrete Research, vol. 38, no. 2, pp. 196-204, 2008.

[10] D. Shen, J. Jiang, J. Shen, P. Yao, and G. Jiang, "Influence of curing temperature on autogenous shrinkage and cracking 
resistance of high-performance concrete at an early age," Construction and Building Materials, vol. 103, pp. 67-76, 2016.

[11] H. Li, J. Liu, Y. Wang, T. Yao, Q. Tian, and S. Li, "Deformation and cracking modeling for early-age sidewall concrete based on the multi-field coupling mechanism," Construction and Building Materials, vol. 88, pp. 84-93, 2015.

[12] K. Olivier, A. Darquennes, F. Benboudjema, and R. Gagné, "Early-age self-healing of cementitious materials containing ground granulated blast-furnace slag under water curing," Journal of Advanced Concrete Technology, vol. 14, no. 11, pp. 717-727, 2016.

[13] R. W. Burrows, The Visible and Invisible Cracking of concrete, ACI International, Farmington Hills, MI, USA, 1998.

[14] N. N. Shi, J. S. Ouyang, R. X. Zhang, and D. H. Huang, "Experimental study on early-age crack of mass concrete under the controlled temperature history," Advances in Materials Science and Engineering, vol. 2014, Article ID 671795, 10 pages, 2014.

[15] L. Wu, N. Farzadnia, C. Shi, Z. Zhang, and H. Wang, "Autogenous shrinkage of high performance concrete: a review," Construction and Building Materials, vol. 149, pp. 62-75, 2017.

[16] Y. Liu, Z. G. Luo, and J. Cao, "Dumbbell test method for evaluation of the early age cracking property of concrete material by stress risers," in Frontiers of Manufacturing Science and Measuring Technology II, Pts 1 and 2, W. P. Sung, J. C. M. Kao, and R. Chen, Eds., vol. 503-504, pp. 473-476, Trans Tech Publications Ltd, Stafa-Zurich, Switzerland, 2012.

[17] A. Z. Bendimerad, E. Rozière, and A. Loukili, "Plastic shrinkage and cracking risk of recycled aggregates concrete," Construction and Building Materials, vol. 121, pp. 733-745, 2016.

[18] P. Rossi, J. L. Tailhan, F.L. Maou, L. Gaillet, and E. Martin, "Basic creep behavior of concretes investigation of the physical mechanisms by using acoustic emission," Cement and Concrete Research, vol. 42, no. 1, pp. 61-73, 2012.

[19] D. Shen, J. Jiang, M. Zhang, P. Yao, and G. Jiang, “Tensile creep and cracking potential of high performance concrete internally cured with super absorbent polymers at early age," Construction and Building Materials, vol. 165, pp. 451-461, 2018.

[20] I. Khan, A. Castel, and R. I. Gilbert, "Tensile creep and earlyage concrete cracking due to restrained shrinkage," Construction and Building Materials, vol. 149, pp. 705-715, 2017.

[21] D. Gawin, F. Pesavento, and B. A. Schrefler, "Hygro-thermochemo-mechanical modelling of concrete at early ages and beyond. Part II: shrinkage and creep of concrete," International Journal for Numerical Methods in Engineering, vol. 67, no. 3, pp. 332-363, 2006.

[22] Y. Gao, J. Zhang, and P. Han, "Determination of stress relaxation parameters of concrete in tension at early-age by ring test," Construction and Building Materials, vol. 41, pp. 152164, 2013.

[23] L. Yue, H. W. Li, Y. N. Li, and C. Y. Jin, "Optimum design of high-strength concrete mix proportion for crack resistance using artificial neural networks and genetic algorithm," Frontiers in Materials, vol. 7, 2020.

[24] S. Subasi, H. Ozturk, and M. Emiroglu, "Utilizing of waste ceramic powders as filler material in self-consolidating concrete," Constr Build Mater, vol. 149, pp. 567-574, 2017.

[25] A. K. Schindler and K. J. Folliard, "Heat of hydration models for cementitious materials," ACI Material Journal, vol. 102, no. 1, pp. 24-33, 2005.
[26] G.D. Luzio and G. Cusatis, "Hygro-thermo-chemical modeling of high performance concrete. I: Theory," Cement and Concrete Composites, vol. 31, no. 5, pp. 301-308, 2009.

[27] M. Sule and K. V. Breugel, "Cracking behaviour of reinforced concrete subjected to early-age shrinkage," Materials and Structures, vol. 34, no. 239, pp. 284-292, 2001.

[28] J. Zhang, Y. Gao, Y. Han, and J. Wang, "Evaluation of shrinkage induced cracking in early age concrete: from ring test to circular column," International Journal of Damage Mechanics, vol. 26, no. 5, pp. 771-797, 2017.

[29] I. Pane and W. Hansen, "Concrete hydration and mechanical properties under nonisothermal conditions," ACI Material Journal, vol. 99, no. 6, pp. 534-542, 2002.

[30] G.D. Schutter and L. Taerwe, "Degree of hydration-based description of mechanical properties of early age concrete," Materials and Structures, vol. 29, no. 190, pp. 335-344, 1996.

[31] D. Shen, J. Jiang, W. Wang, J. Shen, and G. Jiang, “Tensile creep and cracking resistance of concrete with different waterto-cement ratios at early age," Construction and Building Materials, vol. 146, pp. 410-418, 2017.

[32] D. P. Bentz, E. J. Garboczi, and D. A. Quenard, "Modelling drying shrinkage in reconstructed porous materials: application to porous Vycor glass," Modelling and Simulation in Materials Science and Engineering, vol. 6, no. 3, pp. 211-236, 1999.

[33] P. Lura, O. M. Jensen, and K.V. Breugel, "Autogenous shrinkage in high-performance cement paste: an evaluation of basic mechanisms," Cement and Concrete Research, vol. 33, no. 2, pp. 223-232, 2003.

[34] X. Zhai, "Surface of concrete," Concrete Surface Engineering, vol. 5, no. 6, pp. 11-33, 2015.

[35] E. A. B. Koenders and K.V. Breugel, "Numerical modelling of autogenous shrinkage of hardening cement paste," Cement and Concrete Research, vol. 27, no. 10, pp. 1489-1499, 1997.

[36] Y. Liu, A. K. Schindler, and J. S. Davidson, "Finite-element modeling and analysis of early-age cracking risk of cast-inplace concrete culverts," Transportation Research Record: Journal of the Transportation Research Board, vol. 2672, no. 27, pp. 24-36, 2018.

[37] S. Wu, D. Huang, F. B. Lin, H. Zhao, and P. Wang, "Estimation of cracking risk of concrete at early age based on thermal stress analysis," Journal of Thermal Analysis and Calorimetry, vol. 105, no. 1, pp. 171-186, 2011.

[38] W. Jiang, G.D. Schutter, and Y. Yuan, "Degree of hydration based prediction of early age basic creep and creep recovery of blended concrete," Cement and Concrete Composites, vol. 48, pp. 83-90, 2014. 